\section{Análise das portarias ministeriais da saúde e reflexões sobre a condução nacional da política de saúde}

\author{
Analysis of rulings by the Brazilian Ministry \\ of Health and reflections on national \\ health policy management
}

\author{
${ }^{1}$ Escola Nacional de Saúde \\ Pública Sergio Arouca, \\ Fundação Oswaldo Cruz, Rio \\ de Janeiro, Brasil. \\ Correspondência \\ T. W. F. Baptista \\ Departamento de \\ Administração e \\ Planejamento em Saúde, \\ Escola Nacional de Saúde \\ Pública Sergio Arouca, \\ Fundação Oswaldo Cruz. \\ Rua Leopoldo Bulhões 1480 \\ Rio de Janeiro, $R J$ \\ 21041-210, Brasil. \\ twargas@ensp.fiocruz.br
}

\begin{abstract}
Ministry of Health rulings and provisions are important policy regulation tools that aim to orient the enforcement of health-related laws passed by the Legislative Branch, under the terms of the 1988 Federal Constitution. Such provisions have played a major role in the health sector, due not only to the number of documents submitted since the late 1990s, but mainly because of this tool's persuasive power in defining health sector policy. The current article aims to foster reflection on both national health policy management in Brazil and the main obstacles to the implementation of health reform operational aspects. The article classified and analyzed Ministry of Health rulings issued from 1990 to 2002. The study highlights the Ministry's centralizing approach and the use of financial and political persuasion tools that subject State and Municipal governments to the system's rules without creating a negotiated and sustained health policy that the country's institutional realities ratify and support.
\end{abstract}

Health Policy; Executive Power; Health Manager
Tatiana Wargas de Faria Baptista 1

As portarias ministeriais são importantes instrumentos de regulação de políticas e visam, principalmente, a definir instruções para a execução das leis, decretos e regulamentos aprovados pelo Poder Legislativo, tal como previsto na Constituição Federal de 1988, artigo 87.

No contexto do setor saúde, as portarias ministeriais têm assumido um papel de grande destaque, não só pelo quantitativo de documentos apresentados a partir dos últimos anos da década 90, superior a mil portarias/ano, mas principalmente pelo forte poder de indução que este instrumento assumiu na definição da política setorial.

O papel das portarias ministeriais e o caráter indutor assumido na última década revelam uma determinada forma de condução da política de saúde, onde predomina a atuação do Ministério da Saúde e do Poder Executivo Federal, sendo este um padrão de atuação do Estado brasileiro em diversas áreas e não uma característica do setor saúde 1,2. Contudo, tal forma de condução tem suscitado críticas dos mais diversos grupos que interagem com o setor, e, em especial, dos gestores estaduais e municipais e do Conselho Nacional de Saúde.

A principal queixa vocalizada por esses grupos (Conselho Nacional de Saúde. Moção 005/99. http://conselho.saude.gov.br/deliberacoes/mocoes.htm; acessado em 04/Jan/2006) é a dificuldade de se manter atualizado com as novas regras instituídas a cada tempo e a não-regula- 
mentação e, por vezes, modificação de aspectos importantes aprovados nas leis, sem uma participação ampliada dos segmentos interessados, dificultando o amadurecimento da participação social, fragilizando as relações intergovernamentais e não permitindo uma compreensão mais precisa dos objetivos e rumos da política nacional de saúde.

Nesse sentido, a análise da política de saúde a partir das portarias editadas ajuda a compreender melhor o papel que esse instrumento exerce no setor e se de fato tem contribuído ou não para uma centralização decisória no Executivo Federal da saúde.

O objetivo central deste artigo é avançar numa reflexão sobre a condução nacional da política de saúde no Brasil e os principais obstáculos no processo de implementação da reforma. Desenhou-se como estratégia de pesquisa a classificação e análise das portarias ministeriais da saúde editadas, no período de 1990 a 2002, que se destinaram a regulamentar a organização do sistema e a política de assistência à saúde, identificando a correspondência do documento com o momento político-institucional de governo.

O esforço analítico foi de incorporação de uma lógica mais dinâmica de construção e abordagens menos seqüenciais da reforma, considerando que o processo de implementação de uma política por si só configura um quadro de complexidades a ser analisado ${ }^{3}$. Há um consenso entre os estudiosos de políticas públicas que o processo de implementação constitui um elemento chave da política ${ }^{4}$ e que os governos têm sido muito melhores para fazer a legislação do que para efetuar as mudanças desejadas, havendo "brechas de implementação" que merecem ser investigadas 5 .

Este artigo aborda a política pública como uma construção social capaz de formular um conjunto abrangente de políticas, articulando interesses os mais diversos e construindo também diferenciados modelos de intervenção a cada tempo ${ }^{6}$. O foco do estudo está nas políticas de saúde acordadas durante toda a década de 90 e nos dois primeiros anos de 2000, políticas convergentes ou divergentes e que compuseram um quadro possível de análise da ação pública setorial nesse período.

\section{As portarias ministeriais da saúde: principais temas e políticas propostas}

O quantitativo de portarias da saúde com o objetivo de regular a organização do sistema e a assistência à saúde aumentou de forma significativa a partir do ano de 1999, sendo expressiva a partici- pação das portarias da Secretaria de Assistência à Saúde do Ministério da Saúde (SAS/MS) no conjunto, conforme mostra a Tabela 1 .

Para visualizar as políticas desenhadas pelas portarias em cada ano e compreender as razões para o aumento expressivo desses documentos a partir de 1999 e a especificidade de cada discussão, classificou-se a produção por quatro eixos temáticos, como segue abaixo.

\section{- Gestão e organização do sistema e da assistência à saúde}

a) Regulamentação do sistema: normas operacionais, estratégias para a descentralização, planejamento e funcionamento de comissões, regras para o controle e avaliação do sistema, dentre outras;

b) Organização da estrutura: mudanças na estrutura do Ministério da Saúde, cargos, funções e secretarias;

c) Regulamentação de rotinas: organização dos fluxos e práticas gerenciais do sistema;

d) Habilitações: municípios e Estados habilitados conforme as regras das normas operacionais e condições de gestão propostas;

e) Licitações e cadastro: autorização, credenciamento ou descredenciamento para o funcionamento de unidades e serviços de saúde.

\section{- Financiamento}

a) Transferência de recursos: definição e gerência de tetos financeiros para Estados, municípios e Distrito Federal; transferências conforme habilitação dos Estados e municípios definidos nas normas operacionais da saúde e incentivos com recursos específicos para programas, campanhas, ações verticais e estratégicas em saúde; b) Tabelas e procedimentos: remuneração para prestadores de serviço.

\section{- Programas e ações verticais em saúde}

a) Instituição de novos programas e ações verticais;

b) Reformulação e criação de mecanismos de controle dos programas e das ações verticais.

- Outras: temas diversos, dotações orçamentárias, revogando ou anulando outras portarias, estabelecendo a realização de conferências etc.

Numa primeira análise da produção é possível observar (Figura 1) um quantitativo superior das portarias de gestão em todo o período, seguido das portarias de financiamento, que apenas no ano de 1993 apresenta-se em número maior que as portarias de gestão. No entanto, focando 
Tabela 1

Portarias do Ministério da Saúde relativas à organização do sistema e à política de assistência à saúde. Brasil, 1990/2002.

\begin{tabular}{|c|c|c|c|c|c|c|c|}
\hline Anos & GM & SNAS/SAS & INAMPS & SE/SAS & DECAS/SAS & SPS/SAS & Total \\
\hline 1990 & 46 & 10 & 2 & 0 & 0 & 0 & 58 \\
\hline 1991 & 55 & 52 & 36 & 0 & 0 & 0 & 143 \\
\hline 1992 & 61 & 85 & 0 & 0 & 0 & 0 & 146 \\
\hline 1993 & 113 & 112 & 14 & 0 & 0 & 0 & 239 \\
\hline 1994 & 83 & 172 & 0 & 0 & 0 & 0 & 255 \\
\hline 1995 & 80 & 108 & 0 & 0 & 0 & 0 & 188 \\
\hline 1996 & 65 & 200 & 0 & 0 & 0 & 0 & 265 \\
\hline 1997 & 80 & 129 & 0 & 3 & 0 & 0 & 212 \\
\hline 1998 & 123 & 116 & 0 & 0 & 0 & 0 & 239 \\
\hline 1999 & 355 & 649 & 0 & 57 & 0 & 0 & 1.061 \\
\hline 2000 & 356 & 495 & 0 & 31 & 47 & 1 & 930 \\
\hline 2001 & 127 & 562 & 0 & 98 & 32 & 0 & 819 \\
\hline 2002 & 330 & 959 & 0 & 17 & 25 & 0 & 1.331 \\
\hline Total & 1.874 & 3.649 & 52 & 206 & 104 & 1 & 5.886 \\
\hline
\end{tabular}

GM: Gabinete do Ministro; SNAS/SAS: Secretaria de Assistência à Saúde; INAMPS: Instituto Nacional de Assistência Médica da Previdência Social; SE/SAS: Portaria conjunta da Secretaria Executiva e da Secretaria de Assistência à Saúde; DECAS/SAS: Departamento de Controle e Avaliação em Saúde da Secretaria de Assistência à Saúde; SPS/SAS: Portaria conjunta da Secretaria de Políticas de Saúde e Secretaria de Assistência à Saúde.

Fonte: Elaboração a partir do Diário Oficial da União (para o período 1990/1997) e página da Internet do Ministério da Saúde (para o período 1998/2002).

Figura 1

Portarias do Ministério da Saúde por grandes eixos temáticos. Brasil, 1990/2002.

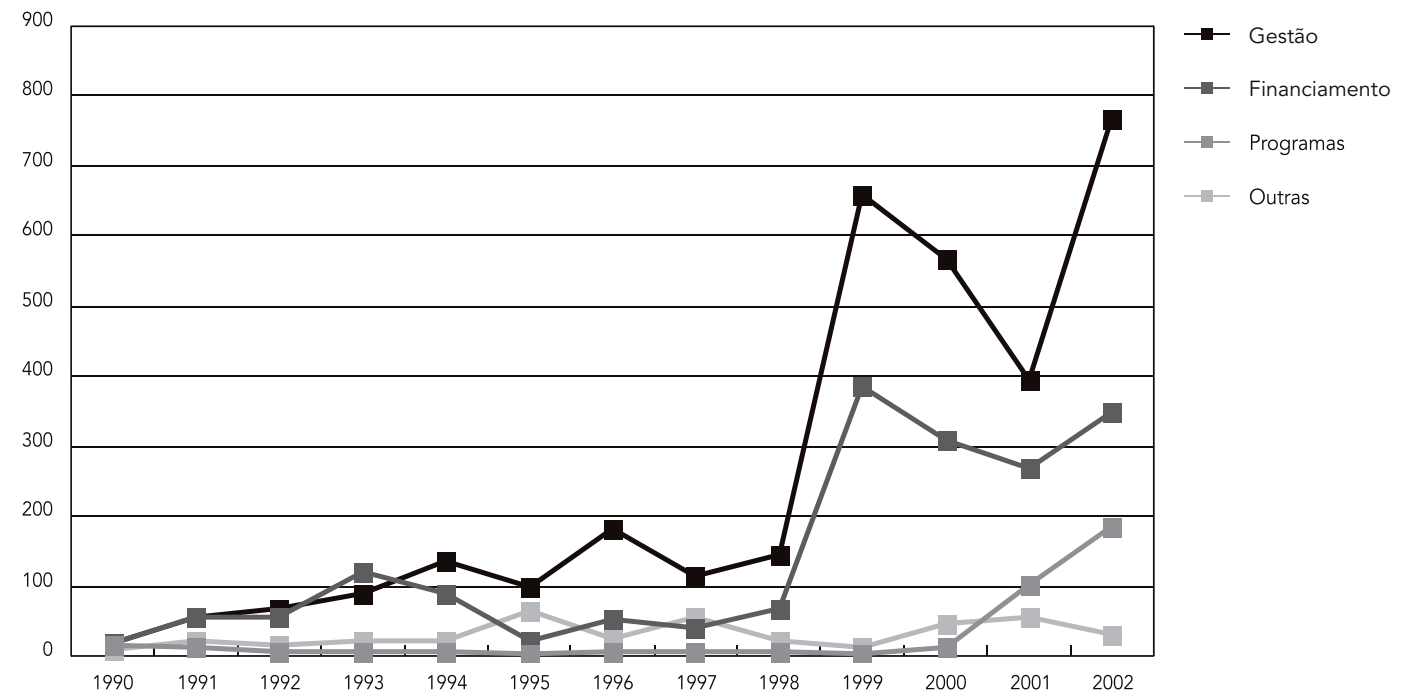

Fonte: Elaboração a partir do Diário Oficial da União (para o período 1990/1997) e página da Internet do Ministério da Saúde (para o período 1998/2002). 
no interior de cada eixo temático o que se evidencia é a freqüência de alguns temas, que associado ao momento político-institucional, configuram outros quadros de análise. Vejamos então como se comportam as portarias em cada eixo identificado.

\section{As portarias de gestão}

No eixo gestão (Figura 2) é significativa a presença das portarias de licitação e cadastro em todo o período. Essas portarias referem-se a todo tipo de autorização, credenciamento ou descredenciamento para o funcionamento de unidades e serviços de saúde a serem ofertados no território nacional. A partir do ano de 1999 há um aumento expressivo dessas portarias, o que se explica pela aprovação e regulamentação da lei sobre remoção de órgãos e tecidos (Lei no. 9.434 7) em 1997 e pela definição de uma política ministerial de incentivo a ações específicas e estratégicas de saúde a partir de 1999 (Fundo de Ações Estratégicas e de Compensação - FAEC) 8 .

Dentre as portarias do Ministério da Saúde, essas são as que mais denotam o resquício de uma função gestora advinda do antigo Ministério da Saúde e do Instituto Nacional de Assistência Médica da Previdência Social (INAMPS), que como prestadores de serviço mantinham o controle das unidades e serviços ofertados.

Tal é o peso dessas portarias no eixo gestão que se as retiramos da contagem de cada ano teríamos uma relação mais balanceada entre as portarias de gestão e as de financiamento, revelando um quantitativo superior das portarias de financiamento em quase todo o período, com exceção dos anos de 1995 a 1998 e do ano 2000 (Figura 3). Ou seja, as portarias de financiamento apareceriam como principais na maior parte do período, expressando o lugar de destaque que ocupam na condução da política nacional de saúde. A importância das portarias de financiamento será discutida quando analisarmos esse eixo, mas é importante destacar o peso que apresentam no conjunto quando retiramos as portarias de licitação, sendo responsáveis por $46 \%$ dos documentos totais, alcançando percentuais acima da média em 8 dos 12 anos analisados.

Retornando a discussão das portarias do eixo gestão, se tomamos como ponto de partida para a análise o debate setorial identificamos como portarias de destaque neste eixo, mesmo sem uma expressão numérica significativa (Figura 2), aquelas que tratam a regulamentação do sistema. Nesse subtema inserem-se as Normas Operacionais da Saúde que assumem um papel de destaque no processo de construção e desenvolvimento do SUS. Foram editadas ao todo seis normas (NOB-91, NOB-92, NOB-93, NOB-96, NOAS-2001 e NOAS-2002), que buscaram definir estratégias para o processo de descentralização na saúde.

Cada gestão de governo editou uma nova norma definindo regras específicas que expressam uma determinada concepção sobre a condução da reforma (Tabela 2). A principal característica das normas é a definição de regras para a descentralização a partir da utilização de mecanismos e incentivos financeiros para a indução de políticas nos estados e municípios, reforçando uma relação tutelar já institucionalizada na condução do Ministério da Saúde, permeando o processo decisório sobre a política de financiamento. Assim, apesar de se tratar de portarias de gestão, estas definem regras de financiamento e, mais uma vez, revelam uma determinada forma de condução da política pelo gestor federal.

Outro aspecto ainda relativo às normas é que apesar de referidas à regulamentação do sistema, na prática se ativeram a regular a descentralização da assistência à saúde, ou seja, uma parte do sistema, deixando de lado um conjunto de ações de saúde de igual importância para a garantia do direito à saúde, como as vigilâncias 9,10.

Dentre as portarias da saúde, as normas são as mais discutidas, ocupando as agendas de reuniões das comissões intergestores, conselhos de saúde e oficinas de trabalho. A discussão das normas possibilitou na última década um amadurecimento dos gestores dos três níveis de governo sobre os problemas e desafios a serem enfrentados na construção do SUS. No entanto, muitas portarias foram editadas após a apresentação das normas, redefinindo ou criando novas regras para o processo apresentado na norma básica. Tal situação configurou-se num problema no processo decisório, pois o que havia sido amplamente discutido e pactuado sofreu reformulações sem uma nova rodada de discussão com os segmentos interessados.

Essa situação ficou explícita no processo de operacionalização da NOB-96. O aumento expressivo do quantitativo de portarias de regulamentação do sistema a partir de 1998/1999, conforme demonstra a figura dois, se deu em função da definição de um conjunto de novas regras e diretrizes substituindo aquelas pactuadas na NOB-96. O que se identificou nesse eixo temático é que a partir de 1997 foi apresentado um conjunto expressivo de portarias reformulando políticas acordadas na gestão anterior, quando se negociou a NOB-96 e quando se estabeleceu pactos para a definição de uma política de atenção básica não restritiva 11. As portarias editadas a partir de 1997 e, principalmente a partir de 1998, sob nova gestão ministerial, apesar de fortalecer 
Figura 2

Portarias do Ministério da Saúde no eixo Gestão. Brasil, 1990/2002.

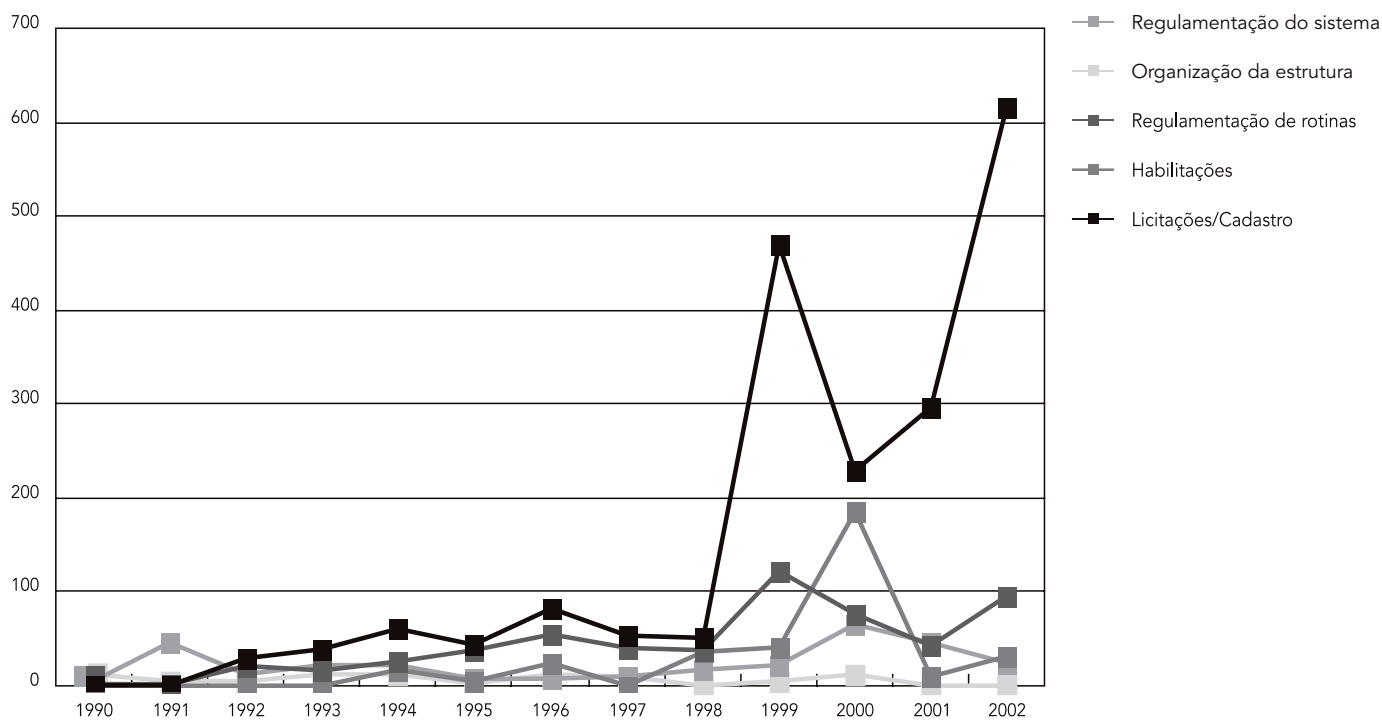

Fonte: Elaboração a partir do Diário Oficial da União (para o período 1990/1997) e página da Internet do Ministério da Saúde (para o período 1998/2002).

Figura 3

Portarias do Ministério da Saúde por grandes eixos temáticos excluindo as portarias de licitação e cadastro de prestadores e serviços. Brasil, 1990/2002.

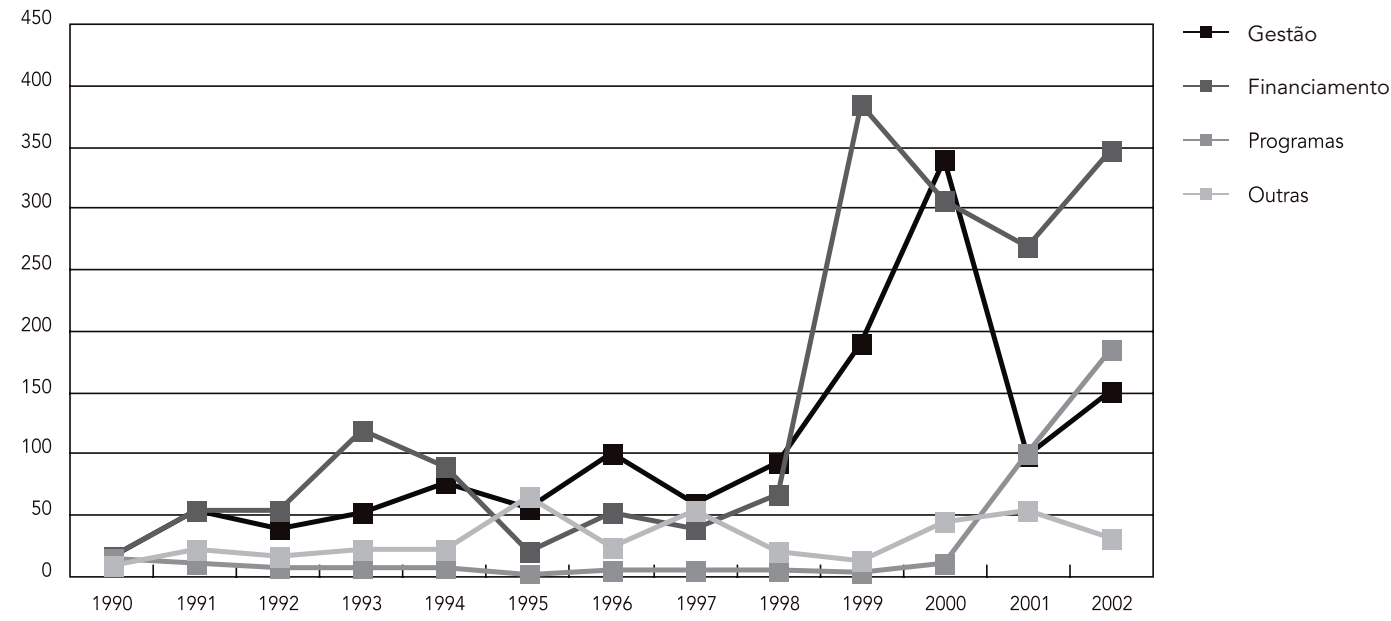

Fonte: Elaboração a partir do Diário Oficial da União (para o período 1990/1997) e página da Internet do Ministério da Saúde (para o período 1998/2002). 
Tabela 2

Normas operacionais da saúde, regras para a descentralização e adoção de incentivos financeiros. Brasil, 1990/2002

\begin{tabular}{lll}
\hline & NOB-91/NOB-92 & NOB-93 \\
\hline $\begin{array}{l}\text { Presidente } \\
\text { Ministro da Saúde }\end{array}$ & Fernando Collor & Itamar Franco \\
$\begin{array}{l}\text { Olceni Guerra } \\
\text { descentralizada da } \\
\text { assistência }\end{array}$ & $\begin{array}{l}\text { Define a política de } \\
\text { financiamento do SUS }\end{array}$ & $\begin{array}{l}\text { Institui condições de gestão } \\
\text { para estados e municípios, } \\
\text { define incentivos financeiros } \\
\text { compatíveis com a condição }\end{array}$ \\
& & $\begin{array}{l}\text { co gestão assumida } \\
\text { de }\end{array}$
\end{tabular}

Alocação de recursos

e transferências

intergovernamentais

\begin{abstract}
Adoção do instrumento de convênio como forma de transferência de recursos do INAMPS para os estados, Distrito Federal e municípios Remuneração por produção de serviços a partir dos sistemas de informações e faturamento (SIA-SUS, ambulatorial e SIH-SUS, hospitalar), tanto para o setor público quanto para o privado
\end{abstract}

Remuneração por produção de serviços apresentados através dos sistemas de informações (SIA e SIH), segundo habilitação municipal e estadual Estabelece critérios de cálculo dos tetos financeiros das atividades ambulatoriais e hospitalares dos estados e municípios habilitados
$\mathrm{Na}$ NOB-92 define $\mathrm{O}$ fator de estímulo à municipalização (FEM) e o fator de estímulo à gestão estadual (FEGE)
Mantém o fator de incentivo ao desenvolvimento do ensino e da pesquisa em saúde para hospitais universitários (FIDEPS) e o Índice de Valorização Hospitalar de Emergência para os hospitais de emergência (IVH-E) Estabelece incentivos financeiros para a descentralização como os fatores de apoio aos estados e municípios (FAE e FAM)

Fernando Henrique Cardoso Fernando Henrique Cardoso

Adib Jatene

Reformula as condições de gestão dos estados e municípios propostas na norma anterior e enfatiza a importância do processo de negociação entre as esferas de governo

Mantém a remuneração por produção de serviços apresentados através dos sistemas de informações Definição do Piso da Atenção Básica (PAB) para estados e municípios habilitados

Define tetos financeiros da assistência do estado e município (TFAE e TFAM)

Define o Piso Básico da Vigilância Sanitária (PBVS) Define teto financeiro de epidemiologia e controle de doenças (TFECD)

Mantém o (IVH-E) Define índices de valorização de resultados (IVR) e de valorização de impacto da vigilância sanitária (IVISA) para estados habilitados PAB variável: PACS, PSF, combate às carências nutricionais, farmácia básica
José Serra/Barjas Negri

Revisa os critérios de habilitação no sentido de promover a responsabilização dos gestores, de forma compatível com a condição de gestão assumida, e induz a integração dos sistemas municipais, sob a coordenação do nível estadual

A Programação Pactuada e Integrada (PPI), aprovada pela Comissão Intergestores Bipartite, norteia a alocação de recursos federais da assistência entre municípios pelo gestor estadual, resultando na definição de limites financeiros claros para todos os municípios do Estado, independente de sua condição de habilitação Define o Piso de Atenção Básica Ampliada (PABA)

Não estabelece nenhum novo incentivo a política de atenção básica não seguiu os parâmetros de discussão propostos no momento de elaboração da NOB-96, mudando a concepção que se tinha do Piso de Atenção Básica (PAB) e introduzindo elementos para uma política de ba- se mais restritiva 12 . Ou seja, se as normas ainda expressam uma tentativa de pactuar e negociar o processo político entre as esferas de governo e representações sociais e de classe, as demais portarias de regulamentação do sistema têm servido 
como um instrumento de poder valioso, onde o principal ator é ainda o gestor federal.

Ainda no eixo gestão, destaca-se o quantitativo de portarias que tratam da regulamentação de rotinas, especialmente nos períodos de 1995/1996 (gestão Adib Jatene) e 1998/2002 (gestão José Serra/Barjas Negri). Essas portarias estão atreladas à organização dos fluxos e práticas gerenciais do sistema e apresentam forte argumento técnico. Na gestão Jatene essas portarias trataram principalmente da construção de critérios para o estabelecimento de repasse de recursos e do estabelecimento de regras explícitas para um melhor gerenciamento do sistema, na perspectiva de habilitar os gestores estadual e municipal no planejamento e programação das ações de saúde. Nesse período ainda era incipiente a organização dos fluxos de informação, alimentação de banco de dados e outras rotinas que respaldam o planejamento, sendo esse um diagnóstico da equipe gestora do Ministério da Saúde, que intencionalmente passou a promover o debate para a construção de rotinas no sistema 13 .

Na gestão Serra/Negri, o enfoque esteve bem mais na definição de procedimentos e rotinas para novas ações, programas e processos de habilitação, em função do processo de implementação da NOB-96, a partir do ano de 1998, e da NOAS-2001, a partir de 2001, bem como a operacionalização dos mecanismos para as ações consideradas estratégicas (FAEC).

Por fim, no eixo gestão inserem-se as portarias de habilitação e de organização de estrutura. As portarias de habilitação surgem como produto do processo instalado pela edição das normas operacionais e da definição de condições de habilitação a partir de 1993. Quando destacamos essas portarias das demais é possível perceber com bastante clareza o ritmo instalado no processo de habilitação dos estados e municípios. De 1994 a 1997 as habilitações se referiam às condições de gestão previstas na NOB-93, enquanto no período 1998/2002 referem-se às condições apresentadas na NOB-96 e NOAS, com um ritmo mais acelerado de habilitação a partir de 1998, com a reformulação de aspectos da NOB-96.

$\mathrm{E}$ as portarias de organização da estrutura definem as mudanças processadas no organograma do Ministério da Saúde - cargos, funções e secretarias -, normalmente acompanhadas de uma legislação no Congresso Nacional (Decreto ou Lei). Em alguns momentos a mudança na estrutura significou uma transformação concreta na forma de condução da política proposta pelo Ministério da Saúde, em outros momentos foram mudanças incrementais apresentadas. São portarias que se apresentam de forma constante em todo o período e que refletem as mudanças de governo e de gestão ministerial, revelando características próprias de cada gestão ministerial. Vale ressaltar as mudanças ocorridas nos dois primeiros anos da década de 90, com a incorporação do INAMPS ao Ministério da Saúde em 1990 e a configuração inicial do novo Ministério da Saúde. A reestruturação do Ministério da Saúde, em 1993, com a extinção do INAMPS, a retomada do Gabinete do Ministro na condução da política e a definição de novas atribuições para a SAS/MS, com o fortalecimento da área, e a reestruturação ministerial a partir de 1997, com a criação de novas secretarias (Secretaria de Políticas), novos departamentos no interior das secretarias, extinção de órgãos (como a Central de Medicamentos - CEME - e o Instituto Nacional de Alimentação e Nutrição - INAN) e criação da Agência Nacional de Saúde Suplementar (ANS) e da Agência Nacional de Vigilância Sanitária (ANVISA), gerando uma estrutura institucional mais complexa e que fragmenta o processo decisório.

Com uma análise das portarias do eixo gestão é possível uma aproximação sobre a forma de condução pelo gestor federal da política de saúde nesses 12 anos.

Há uma tendência do gestor federal em manter o poder de áreas que poderiam ser estrategicamente repassadas para os estados, como no caso das portarias de licitação e cadastro; essa passagem deve se dar de forma gradativa e parcial, na perspectiva de desatrelar do Ministério da Saúde a função de prestação de serviços e de garantir maior responsabilização dos entes federativos, mas pouco tem sido feito nesse sentido, ao contrário, o Ministério da Saúde tem proposto novos programas e ações que intensificam ainda mais a função de prestação e execução de serviços.

Na regulamentação do sistema, o Ministério da Saúde fortaleceu e definiu regras prioritariamente para a área da assistência à saúde e reforçou uma lógica segmentada e fragmentada do processo decisório, dificultando a construção de uma política de saúde integral e articulada entre a assistência e as vigilâncias. Ao final do período, especialmente a partir de 1997, constituiu um conjunto de novas áreas e departamentos no interior das secretarias, fragmentando ainda mais o sistema. Mesmo no que tange à assistência à saúde, reforçou a segmentação com a definição de estratégias e incentivos diferenciados para a baixa, média e alta complexidade do sistema.

Na definição das regras para a regulamentação do sistema, o gestor federal buscou base de apoio na aprovação das normas operacionais da saúde, inaugurando e fortalecendo uma prática mais democrática de negociação e pactuação das diretrizes a serem implementadas pelos ges- 
tores estaduais e municipais. Mas também um conjunto expressivo de regras para o sistema foi aprovado sem o conhecimento e a discussão desses mesmos segmentos, denunciando uma condução ainda concentradora de poder. Considerando que as portarias de regulamentação do sistema definem instrumentos para organização e orientação da política nacional e que os entes federativos deveriam estar implicados na construção dessa política, parece essencial a participação e negociação entre os três segmentos dos elementos que devem reger a política nacional, bem como das estratégias para o nível local.

Cabe ainda ressaltar que há uma escassez de regulamentações relativas ao planejamento, controle e avaliação do sistema, evidenciando a fragilidade do gestor federal na função planejamento. A fragilidade dessa função gestora também se expressa na análise das portarias de regulamentação de rotinas, que surgem muito mais como elementos para a definição de estratégias de curto prazo do que para a construção de bases mais sustentadas para a organização do sistema.

\section{As portarias de financiamento}

Nas portarias de financiamento foi possível verificar um quantitativo constante de documentos nos dois subtemas: transferência de recursos e tabela de procedimentos (Figura 4). As inflexões perceptíveis nesse quantitativo estão relacionadas a um aumento no número de portarias sobre valores de tabelas e procedimentos, no período de 1991 a 1994, e na de transferência de recursos, nos anos de 1993 e 1994, e o aumento colossal de portarias relativas à transferência de recursos e em menor número nas portarias sobre valores de tabelas e procedimentos, a partir de 1999. As explicações para essas variações podem ser atribuídas a:

- Mudanças nos valores de tabelas e procedimentos nos anos de 1991 e 1992 associadas às regras propostas pela NOB-91, com ênfase no pagamento por produção;

- Nos anos de 1993 e 1994, tanto tabelas de procedimentos como regras de transferência são resultados da edição da NOB-93 e da criação de incentivos para as condições de habilitação de

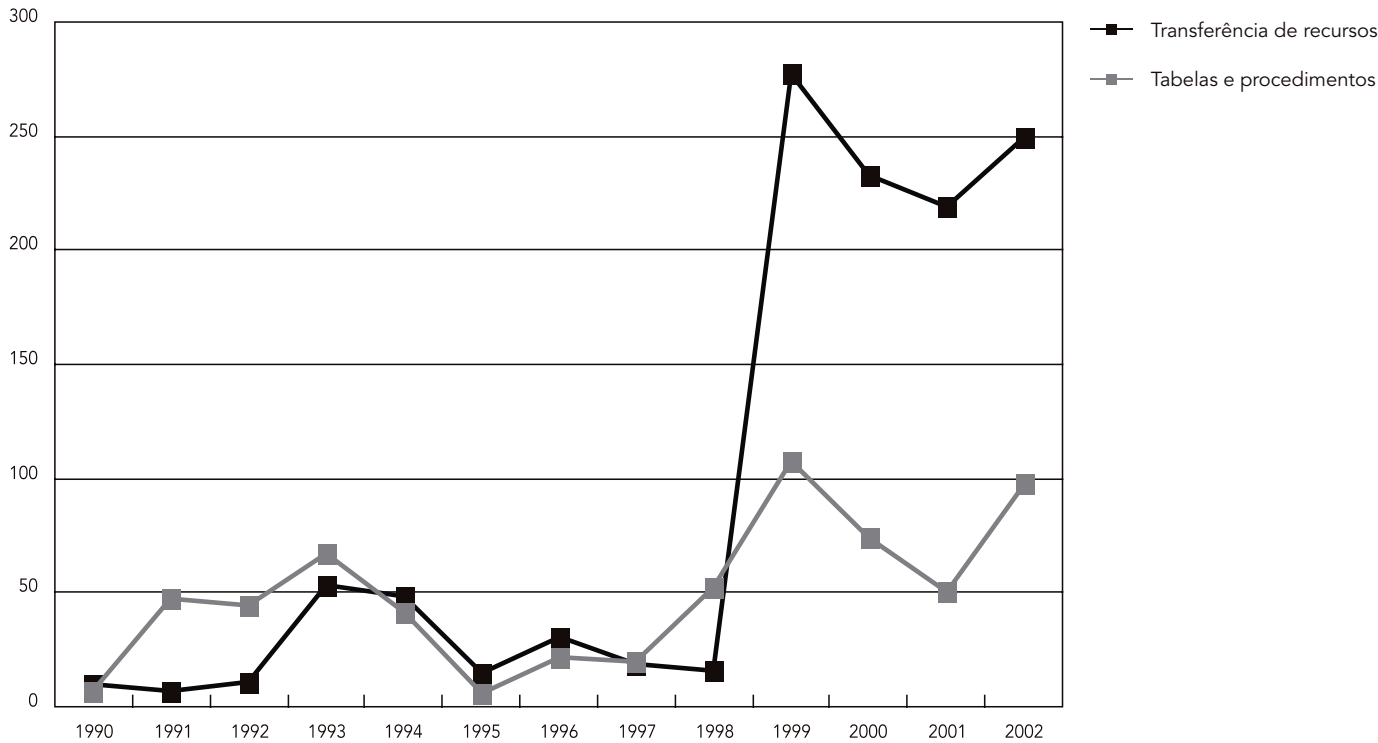

Fonte: Elaboração a partir do Diário Oficial da União (para o período 1990/1997) e página da Internet do Ministério da Saúde (para o período 1998/2002). 
Estados e municípios, como os Fatores de Apoio a Municípios (FAM) e Fatores de Apoio a Estados (FAE), e principalmente a definição de tetos e incentivos financeiros;

- A partir de 1999, como resultado da reorganização da política proposta na NOB-96, reformulada a partir de 1998 (definição de tetos e incentivos financeiros), e da política de incentivo a programas e ações estratégicas (FAEC e novos programas).

Mas a principal diferença entre os períodos e as portarias editadas no que tange ao financiamento esteve no quantitativo de documentos que se produziu, denunciando o uso excessivo dessa estratégia a partir de 1999. Os gestores passaram a se ressentir com a apresentação constante de novas regras para repasse dos recursos, o que os impossibilitava de acompanhar ou mesmo interferir nas propostas apresentadas pelo Ministério da Saúde, tendo como principal problema o fato de que essas portarias muitas vezes rompiam pactos estabelecidos e se impunham como política para o nível local.

Dentro do eixo de financiamento o subtema que trata da transferência de recursos ocupa um lugar central no processo de implementação das políticas, pois é nessa área que se exerce o poder de definir e de induzir a política. Por outro lado, como são portarias específicas que regulam a transferência de recursos, muitas vezes, não passam por discussões ampliadas ou mesmo mais aprofundadas sobre o que está sendo proposto, diferente das portarias que tratam da regulamentação do sistema, onde se incluem as normas. Ou seja, as normas como portarias que definem uma macroestratégia de política têm sido bem mais discutidas do que as portarias que regulamentam as estratégias previstas nas normas. Esse tem sido um ponto de conflito entre o gestor federal e os gestores estaduais e municipais, que reivindicam maior autonomia e o cumprimento dos pactos estabelecidos no momento de formulação das normas e demais portarias de regulamentação do sistema e financiamento.

Também as portarias que tratam de recursos, tetos financeiros Estaduais e municipais, incentivos, valores de tabelas e procedimentos (subtema 2), são áreas de pouca discussão, onde os parâmetros não estão claros ou postos sobre a mesa, permitindo uma baixa intervenção dos Estados e municípios e mesmo das demais áreas do Ministério da Saúde na sua formulação e acompanhamento. Na questão específica dos valores de tabelas e procedimentos a discussão é ainda mais difícil, pois se refere a parâmetros técnicos e séries de gastos que dificultam a compreensão desse processo.
As conseqüências mais visíveis da política de intransparência imposta nas portarias de financiamento se explicitam na relação dos Estados e municípios com o Ministério da Saúde, onde aqueles preferem manter sua parcela de recursos intocada e garantir os recursos como prestadores de serviço e cumpridores das regras estabelecidas. Uma posição bastante cômoda porque não exige uma revisão do quanto gastam ou investem na saúde e mantêm a estrutura de poder já estabelecida, por isso tem sido tão difícil fazer com que se discuta, por exemplo, tetos estaduais, porque discutir significa rever quem ganha mais ou menos e redistribuir 13 .

Nessa questão insere-se ainda um debate maior sobre o financiamento do setor saúde. Essa não é uma questão regulada nessas portarias, mas que está implícita.

Primeiro não se discute valores de tabelas e procedimentos porque esses valores não podem ultrapassar alguns patamares, sua real revisão exigiria um incremento de gastos nesse setor, ou uma recomposição das prioridades de gasto, o que não tem se apresentado na agenda de discussão dos últimos governos. Apenas na gestão Jatene (segunda gestão: 1995/1996) foi feita uma proposta de revisão das tabelas, o que não teve apoio político e, portanto, não teve prosseguimento. As revisões de tabelas processadas nos últimos anos servem bem mais como um mecanismo de incentivo para uma política a ser implementada (vide as políticas desenhadas para a implementação de ações específicas - FAEC) do que numa lógica de mudança radical dos parâmetros estabelecidos para os procedimentos de uma maneira geral, sem a discriminação de ações ou vínculo com programas.

Segundo porque a revisão de tetos financeiros e recursos para incentivos também exige um maior aporte de recursos, é impossível discutir redistribuição se o que se propõe redistribuir são misérias, que se diminuídas significa o sacrifício maior de uma ou outra população, já sacrificada - nenhum secretário de saúde municipal ou estadual está disposto a discutir seu teto quando o que já recebe não lhe garante o mínimo para sua população; discutir o teto nessas circunstâncias corresponde a uma situação de suicídio político, mesmo considerando a responsabilidade dos Estados e municípios no financiamento da saúde.

Associado a esse debate está a questão das séries históricas e dos parâmetros para a definição dos procedimentos. A opção de se trabalhar com séries históricas de gastos e fixar diretrizes para o repasse de recursos nessas séries também reafirma a desigualdade já existente. As séries estão longe de expressar as necessidades de saúde e os gestores não têm outra opção de discussão 
do que brigar pelo recurso mínimo para sua região. Aqui também se expressa a força do argumento técnico, quer pelas normas que regulam e especificam a forma de transferência do recurso, quer pelo critério que determina o valor de um procedimento.

Como pano de fundo de toda essa questão está o pacto federativo, o projeto político de Estado e o papel que ocupa a política social e de saúde nesse projeto - o modelo de proteção social que se deseja constituir. As regras de repasse de recursos só poderão ser modificadas se houver uma mudança nesse patamar de discussão. Isso nos dá clareza para afirmar que não serão as pequenas mudanças propostas no bojo das portarias de financiamento do Ministério da Saúde que trarão conseqüências para a saúde da população ou para a forma de organização do sistema. Que o fato dessas portarias terem sido muito criticadas nos últimos anos, especialmente pelo aumento expressivo de documentos produzidos a partir de 1999, indica muito mais uma disputa de poder entre as três esferas de governo do que a busca de uma estratégia para a materialização de uma melhora do padrão da atenção à saúde.

É necessário avançar numa análise crítica dos parâmetros e regras criadas pelo sistema nos últimos anos, no que elas reproduzem e o que de fato se deseja constituir como política de saúde. De fato, nos últimos anos, o quantitativo de portarias que regulam a questão do financiamento e o repasse de recursos da esfera federal aumentou muito, sem uma discussão prévia nas instâncias que têm a função de formular, controlar e acompanhar o SUS (Comissão Intergestores Tripartite e Conselho Nacional de Saúde). Essas portarias introduzem mudanças na forma de organização do sistema que são de difícil apreensão ou percepção no momento em que são apresentadas. Por outro lado, como são portarias que, na sua grande maioria, atrela incentivos de financiamento à adoção de determinadas políticas e práticas pelos gestores estaduais e municipais, passam a ser incorporadas por estes sem uma discussão mais coerente com os princípios a serem construídos no SUS.

Assim, a questão do financiamento é bem mais complexa. A política de financiamento ocupa um lugar de destaque na condução da política nacional de saúde dada a capacidade de indução que este instrumento apresenta. As portarias de financiamento cumprem determinações dispostas nas portarias de regulamentação do sistema, especialmente as normas, e extrapolam a discussão das normas quando definem por outros critérios, de forte argumento técnico, quais são as prioridades, quanto alocar e como fazer. O financiamento é uma ferramenta de poder do
Ministério da Saúde que tem sido utilizada de forma desbalanceada no processo de operacionalização da reforma.

A estratégia de repasse de recursos por metas, ações ou compromissos firmados pelos Estados e municípios junto ao Ministério da Saúde se sustentou durante todo período frente às dificuldades reais no processo de descentralização política e decisória para as esferas subnacionais de governo, o que se expressa em documentos oficiais e debates institucionais que tratam da questão 14 .

O outro lado dessa questão, pouco debatido ou explicitado, é o diagnóstico da dificuldade do Ministério da Saúde em construir um modo alternativo de fazer política que não seja a forma indutora e concentradora de poder, com uma nítida herança de gerenciar serviços, seja do modo de gerir do INAMPS ou do Ministério da Saúde pré-SUS. As instituições que hoje compõem o Ministério da Saúde sempre foram muito mais prestadoras de serviço do que gestoras do sistema, o que nos faz acreditar que o gestor federal também tem um problema de identidade, suas competências não estão claramente definidas e o papel gestor da esfera federal ainda não foi discutido com profundidade.

\section{As portarias sobre programas e ações verticais em saúde}

O terceiro eixo de portarias especifica a instituição, reformulação e criação de mecanismos de controle dos programas e outras ações verticais em saúde. Durante todo o período surgiram portarias mantendo essa prática, o que também revela uma forma de atuar bastante própria das instituições de origem do SUS, mas é possível verificar o peso atribuído a essa política nos últimos anos do período analisado (2001 e 2002) (Figura 1), quando muitos programas foram retomados e reformulados, definindo novos incentivos e modalidades de transferência de recursos. No ano de 1997 há um retorno da lógica de constituição dos programas verticais de saúde para a definição de ações de controle e combate específico de algumas doenças. Tal estratégia é aperfeiçoada a partir desse ano com a introdução de um mecanismo de financiamento - FAEC - em 1999, com o objetivo de desenvolver e subsidiar ações consideradas estratégicas para o governo federal, reforça a ênfase já dada nas ações programáticas e na política de indução pelo financiamento. Dentre as ações estratégicas estão aquelas voltadas para grupos populacionais prioritários e para a ampliação de acesso dos usuários do SUS aos procedimentos com grande demanda reprimida, como as cirurgias eletivas (próstata, varizes, ca- 
tarata etc.), e novas ações programáticas, como a humanização do parto, a triagem neonatal e a assistência ao portador de deficiência e ao portador de transtornos decorrentes do uso de álcool e drogas 8 .

\section{Elementos para análise sobre a condução nacional da política de saúde}

A análise das portarias editadas no período de 1990-2002 já permite a identificação de alguns elementos críticos na condução nacional da política de saúde no Brasil e de alguns obstáculos no processo de operacionalização da reforma.

O que percebemos da ação do Ministério da Saúde são ainda os resquícios de uma prática centralizadora e vertical, utilizando-se de instrumentos de indução política que muito mais submetem os níveis subnacionais de governo às regras do sistema do que de composição de uma política acordada e sustentada de saúde nas diversas realidades institucionais do país e respaldada numa prática social concreta. Essa forma de atuar se reforça e se mantém por uma postura também de acomodação das demais esferas de governo, que ainda percebem na relação de tutela com o Ministério da Saúde a garantia de benefícios e recursos para dar sustentação às suas políticas locais sem uma responsabilização maior de seus orçamentos próprios ou o compromisso com uma agenda política mais extensiva. De fato, tem sido mais fácil criticar o Ministério da Saúde pela centralização decisória e indução financeira dos recursos do que criticar os Estados e municípios no esforço para a elaboração de políticas locais condizentes com as necessidades de suas regiões.

Mesmo assim, extraímos da análise das portarias algumas conclusões gerais que servem como ponto de partida para uma discussão mais específica das opções políticas de cada gestão do Ministério da Saúde nos 12 anos apurados.

As normas operacionais da saúde assumiram um papel de destaque no processo de construção e desenvolvimento do SUS, tendo se configurado durante todo o período como a principal estratégia para a operacionalização da política; foram editadas ao todo seis normas (NOB-91, NOB-92, NOB-93, NOB-96, NOAS-2001 e NOAS-2002), cada qual corresponde a uma gestão de governo e expressa uma concepção específica sobre a forma de condução da política nacional.

No ano de 1997 há um retorno da lógica de constituição dos programas verticais de saúde para a definição de ações de controle e combate específico de algumas doenças. Tal estratégia é aperfeiçoada a partir desse ano com a introdução de um mecanismo de financiamento - FAEC em 1999, com o objetivo de desenvolver e subsidiar ações consideradas estratégicas para o governo federal, reforçando a ênfase já dada nas ações programáticas e na política de indução pelo financiamento.

A política de assistência à saúde predomina em todo o período e mais enfaticamente a partir de 1998, acentuando a fragmentação do processo decisório na saúde e a reafirmação do poder institucional da área da assistência. A divisão da assistência na atenção básica, média e alta complexidade é um outro fator que reforça a fragmentação na condução da política, inclusive no contexto da assistência.

Nesse sentido, as portarias têm servido como um valioso instrumento de poder, reforçando o papel concentrador do Executivo federal que edita portarias que tanto podem validar como desfazer pactos estabelecidos em leis ou mesmo em outras portarias. $\mathrm{O}$ argumento técnico mascara uma opção política dos governos na definição das diretrizes políticas para a saúde, como no caso do financiamento em que não se discute de forma transparente os critérios para a definição dos valores de tabelas e procedimentos, e a definição dos tetos e incentivos financeiros. Há um acordo implícito entre os gestores, federal, estadual e municipal, para a não revisão dos parâmetros, pois isso significaria uma perda de recursos e um debate real sobre as opções políticas em torno de um modelo de proteção social e a reformatação do pacto federativo. Por outro lado, as portarias de regulamentação do sistema são de fato portarias de regulamentação da assistência à saúde no seu sentido estrito, o que significa que todos os mecanismos elaborados durante os 12 anos fortaleceram apenas uma área do setor saúde, reforçando a fragmentação decisória na saúde e impedindo a construção de uma política de fato integral em saúde.

Por fim, a análise das portarias nos permite questionar o quanto o Ministério da Saúde tem conseguido atuar na construção de uma política nacional de saúde de bases mais sólidas. O que se expressa é um esforço grande na regulamentação de estratégias de curto prazo em atenção às propostas políticas de cada gestão de governo, em detrimento de políticas de médio e longo prazos, capazes de articular gestores estaduais e municipais e a sociedade civil, por mais de uma gestão de governo, um projeto político para a saúde no país. 


\section{Resumo}

As portarias ministeriais são importantes instrumentos de regulação de políticas e visam a definir instruções para a execução das leis aprovadas pelo Poder Legislativo, tal como previsto na Constituição Federal de 1988. No contexto do setor saúde, as portarias têm assumido um papel de grande destaque, não só pelo quantitativo de documentos apresentados a partir dos últimos anos da década 90, mas principalmente pelo forte poder de indução que este instrumento assumiu na definição da política setorial. O objetivo do artigo é avançar na reflexão sobre a condução nacional da política de saúde no Brasil e os principais obstáculos na

\section{Referências}

1. Amorim Neto O. O Poder Executivo, centro de gravidade do sistema político brasileiro. In: Avelar L, Cintra AO, organizadores. Sistema político brasileiro: uma introdução. Rio de Janeiro: Fundação Konrad-Adenauer-Stiftung/São Paulo: Fundação Unesp; 2004. p. 123-34.

2. Pessanha C. O poder executivo e o processo legislativo nas constituições brasileiras. Teoria e prática. In: Vianna LW, organizador. A democracia e os três poderes no Brasil. Belo Horizonte: Editora UFMG/Rio de Janeiro: Instituto Universitário de Pesquisas do Rio de Janeiro/Fundação de Amparo à Pesquisa do Estado do Rio de Janeiro; 2003. p. 141-93.

3. Walt G. Health policy. An introduction to process and power. London: Zed Books; 1996.

4. Mémy Y, Thoenig J-C. Las políticas públicas. Barcelona: Editorial Ariel; 1992.

5. Hogwood BW, Gunn LA. Policy analysis for the real world. Oxford: Oxford University Press; 1984.

6. Muller P, Surel Y. L'analyse des politiques publiques. Paris: Montchrestien; 1998.

7. Brasil. Lei no. 9434. Dispõe sobre a remoção de órgãos, tecidos e partes do corpo humano para fins de transplante e tratamento. Diário Oficial da União 1997; 5 fev.

8. Ministério da Saúde. Reduzindo as desigualdades e ampliando o acesso à assistência à saúde no Brasil: 1998-2002. Brasília: Ministério da Saúde; 2002. operacionalização da reforma. Foi realizada a classificação e análise das portarias do Ministério da Saúde editadas no período de 1990 a 2002. O estudo revela a manutenção de uma prática centralizadora por parte do Ministério da Saúde e o uso de instrumentos de indução política e financeira que submetem os níveis subnacionais de governo às regras do sistema, sem a composição de uma política acordada e sustentada de saúde nas diversas realidades institucionais do país.

Política de Saúde; Poder Executivo; Gestor de Saúde
9. Levcovitz E. Transição e consolidação: o dilema estratégico da construção do SUS. Um estudo sobre as reformas da política nacional de saúde [Tese de Doutorado]. Rio de Janeiro: Instituto de Medicina Social, Universidade do Estado do Rio de Janeiro; 1997.

10. Levcovitz E, Lima LD, Machado CV. Política de saúde nos anos 90. Relações intergovernamentais e papel das normas operacionais básicas. Ciênc Saúde Coletiva 2001; 6:269-91.

11. Carvalho G. A inconstitucional administração pósconstitucional do SUS através de normas operacionais. Ciênc Saúde Coletiva 2001; 6:435-44.

12. Baptista TWF. Políticas de saúde no pós-constituinte: um estudo da política implementada a partir da produção normativa dos poderes executivo e legislativo no Brasil [Tese de Doutorado]. Rio de Janeiro: Instituto de Medicina Social, Universidade do Estado do Rio de Janeiro; 2003.

13. Lima LD, Baptista TWF. Seminário Programação Pactuada e Integrada da Assistência: limites e possibilidades para alocação de recursos e ampliação do acesso às ações e serviços de saúde. Relatório Síntese. Rio de Janeiro: Escola Nacional de Saúde Pública, Fundação Oswaldo Cruz; 2003.

14. Ministério da Saúde. Descentralização das ações e serviços de saúde: a ousadia de cumprir e fazer cumprir a lei. Brasília: Ministério da Saúde; 1993.

Recebido em 11/Jan/2006 Aprovado em 18/Jul/2006 